\title{
Atomic-configuration Modulation of Active Sites on Electrocatalysts
}

Lili Han and Huolin Xin

University of California-Irvine, Coram, New York, United States

An active site on the surface of a catalyst is the ensemble of atoms that directly catalyzes a reaction, such as carbon dioxide electrochemical reduction $\left(\mathrm{CO}_{2} \mathrm{ECR}\right)$, nitrogen reduction reaction (NRR), hydrogen evolution, oxygen evolution, oxygen reduction and others.[1-3] Modulating the atomic configurations of active sites is crucial and highly desired for improving the properties of catalysts and controlling catalysis.[4,5] However, it is highly challenging to modulate the atomic configuration of active sites and enable the confident control of active sites at atomic level. In this talk, with the guide of our density functional theory calculations, we have experimentally realized the modulation of the atomic configuration of active sites on MoC nanoparticle surfaces and single-atom catalysts for significant enhanced $\mathrm{CO}_{2} \mathrm{ECR}$ and NRR, respectively. This atomic-level modulation is well confirmed by atomicresolution high-angle annular dark-field scanning transmission electron microscope (HAADF-STEM) imaging, high-resolution 3D electron tomography and other techniques.

The modulation adjusts the potential-limiting step of the electrocatalytic reduction of $\mathrm{CO}_{2} \mathrm{ECR}$ to $\mathrm{CH}_{4}$ on the $\mathrm{MoC}$ nanoparticles. Consequently, the Faradaic efficiency $(\mathrm{FE})$ of the $\mathrm{CO}_{2} \mathrm{ECR}$ to $\mathrm{CH}_{4}$ is enhanced 5 times in aqueous solutions at ambient conditions. This high FE value fluctuates within a narrow range for 50 hours, indicating high stability. This modulation strategy provides new opportunities to effectively improve the activities of catalysts and eliminate the $\mathrm{OH}$ poisoning by precisely decorating metal active sites with heterogeneous atomic patterns. Moreover, the modulated single-atom catalysts for NRR achieved an FE increase by $2 \%$ and an $\mathrm{NH}_{3}$ yield rate increase by $49.28 \mu \mathrm{g} \mathrm{h}^{-1} \mathrm{mg}_{\text {cat. }}{ }^{-1}$ at $-0.35 \mathrm{~V}$. The enhanced NRR performance is ascribed to their unique geometry and electronic structure, which not only facilitate the adsorption and activation of $\mathrm{N}_{2}$ molecule but also lower the free energy change of the potential-determining step.

\section{References}

[1] Chung, H. T., Cullen, D. A., Higgins, D., Sneed, B. T., Holby, E. F., More, K. L. \& Zelenay, P. Science 357, 479-484 (2017).

[2] Han, L., Liu, X., Chen, J., Lin, R., Liu, H., Lu, F., Bak, S., Liang, Z., Zhao, S., Stavitski, E., Luo, J., Adzic, R. R. \& Xin, H. L., Angew. Chem. Int. Ed. 58, 2321-2325 (2019).

[3] Han, L., Meng, Q. P., Wang, D. L., Zhu, Y. M., Wang, J., Du, X. W., Stach, E. A \& Xin, H. L., Nat. Commun. 7, 13335 (2016).

[4] Zhang, L., Han, L., Liu, H., Liu, X. \& Luo, J. Angew. Chem. Int. Ed. 56, 13694-13698 (2017).

[5] Ling, T., Yan, D. Y., Jiao, Y., Wang, H., Zheng, Y., Zheng, X., Mao, J., Du, X. W., Hu, Z., Jaroniec, M. \& Qiao, S. Z. Nat. Commun. 7, 12876 (2016). 